\title{
Erratum to: Elucidating the neurophysiological underpinnings of autism spectrum disorder: new developments
}

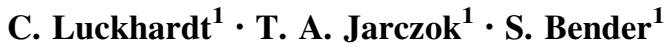

Published online: 7 July 2015

(c) Springer-Verlag Wien 2015

Erratum to: J Neural Transm (2014)

\section{1:1129-1144}

DOI 10.1007/s00702-014-1265-4

The author would like to correct the errors in the publication of the original article. The corrected details are given below for your reading.

In the second footnote of page number 1133, Last sentence should read as:

For a detailed discussion of this subject see e.g. Earp and Everett (2013).

In the right column of page number 1142, second reference from bottom should read as

Earp BD, Everett JAC (2013) Is the N170 face specific? Controversy, context, and theory. Neuropsychol Trends 13(1):7-26.

The online version of the original article can be found under doi:10.1007/s00702-014-1265-4.

C. Luckhardt

Christina.Luckhardt@kgu.de

1 Department of Child and Adolescent Psychiatry,

Psychosomatics and Psychotherapy, JW Goethe University

Frankfurt, Deutschordenstraße 50, 60528 Frankfurt am Main,

Germany 